\title{
Phytoplankton Diversity of Jiaolai Estuary in Laizhou Bay and Relationship with Oceanic Environmental Factors
}

\author{
Haodong Gao ${ }^{1,}$, Xueyan Sun ${ }^{1, b}$ \\ ${ }^{1}$ Yantai Institute, China Agriculture University, Yantai, Shandong, China 264670 \\ aoceangog@163.com, bsdmmb2000@163.com
}

Keywords: Laizhou Bay; Phytoplankton community; Correlation analysis; Environmental factors.

\begin{abstract}
Phytoplankton community structure and environmental factors of Jiaolai Estuary and adjacent waters in Laizhou Bay were investigated in October, 2015. Affected by high-concentration salt-containing wastewater discharged in east coasts, the water quality of investigated waters showed a trend of high salinization. 17 genera and 25 species were authenticated and diatom dominated. Phytoplankton species and abundance decreased obviously compared with those in the same period of previous years and the trend of change was increasing from the estuary and coasts to the outside, which was in contrast with distribution characteristics of phytoplankton in typical estuarine coastal waters. In addition to the nearshore alga species such as Melosira sulcata, offshore high-salt specie Cos. asteromphalus also became one of the dominant species in investigated waters. Results of multivariate statistics divided the phytoplankton community into three ecological groups, including Group I of an estuarine type in Jiaolai Estuary, Group II of a coastal low-salt type in east coasts of Jiaolai Estuary, and Group III of a high-salt, low-nutrition type near the main drain outlets of the industrial park. Correlation analysis showed that salinity and transparency were the main factors affecting the phytoplankton community composition of the investigated sea area.
\end{abstract}

\section{Introduction}

As the primary producer of the entire water ecosystem, changes of phytoplankton species and numbers are closely related with surrounding factors and it gives the most direct response to the change of an aquatic ecological environment [1]. International policies and regulations such as EU Water Framework Directive and Marine Strategy Framework Directive put forward that characteristics of phytoplankton structure are important indexes of water quality assessment and water ecology conditions [2, 3]. Jiaolai River is an important runoff to the sea in Laizhou Bay and a wide area of chemical industrial parks lies on the east coasts of its estuary. Discharge of large industrial high-salt wastewater led to the deterioration of water quality and severe atrophy of low-salt areas in Jiaolai Estuary and adjacent waters near the east coasts, threatening the quality of the ecological environment seriously. Phytoplankton community structure and main environmental impact factors were studied in this sea area in autumn, 2015, providing bases about theoretical research and optimization decision for marine environmental protection, pollution prevention and sustainable development of marine economy.

\section{Sites, Materials and Methods}

Sites descriptions. In October, 2015, 8 sampling sites were set up in Jiaolai Estuary and its adjacent waters in Laizhou Bay (Fig.1). LZW1 LZW3 were located within Jiaolai Estuary and on its diluted water and LZW4 LZW8 were located on coastal waters of Yinhai Industrial Park on the east side of Jiaolai Estuary. LZW4, LZW6 and LZW8 were around discharge outlets and LZW6 lied on an area with maximum discharge of most concentrated salinity wastewater. 


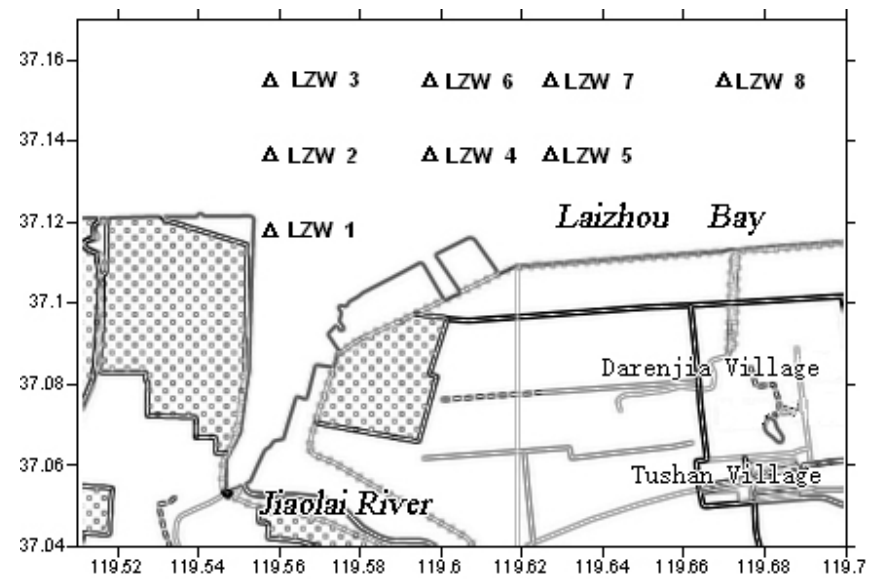

Fig. 1 Sampling sites in Jiaolai Estuary and its adjacent waters

Sampling. Shallow-water type III plankton nets were applied in the collection of phytoplankton. Vertical trawl was conducted from a seabed to a sea level in each site and 5\% Lugol's solution was added dropwise in samples for preservation. According to "Specifications for Oceanographic Survey", various determinations and cell counting were conducted in laboratories. Collection and treatment of water samples and analysis and determinations of various environmental parameters were in line with methods in "Specifications for Marine Monitoring".

Statistics and analysis. Dominance $Y$ was used to evaluate dominant species in this sea water. Shannon-Wiener diversity indexe $\left(H^{\prime}\right)$, Margalef richness indexe $(D)$ and Pielou evenness indexe $(J)$ were integrated to analyze the diversity of phytoplankton in the target sea waters [4].

Sufer 8.0 was utilized to draw profiles of sites and contour maps of spatial distribution of various parameters. Primer 6.0 was used to conduct multivariate statistics combining CLUSTER and MDS on species for division of community structures. Significance of differences among community structures was tested by the ANOSIM method. Pearson correlation analysis was used to explain relations between phytoplankton community data and environmental data [5].

\section{Results and Discussion}

Physico-chemical characteristics. As shown in Tab. 1, differences of monitoring value of main environmental factors in various sites were large to form a certain spatial distribution pattern.

Tab.1 The important environmental factors in Jiaolai estuary and its adjacent waters

\begin{tabular}{clllllllll}
\hline Parameter & LZW1 & LZW2 & LZW3 & LZW4 & LZW5 & LZW6 & LZW7 & LZW8 & MEAN \\
\hline SAL & 38.6 & 31.9 & 31.7 & 40.7 & 35 & 42.1 & 33.2 & 35.9 & 36.14 \\
COD & 2.56 & 2.5 & 2.48 & 2.42 & 2.4 & 2.34 & 2.29 & 2.32 & 2.41 \\
DIN & 0.208 & 0.208 & 0.206 & 0.191 & 0.194 & 0.199 & 0.178 & 0.17 & 0.19 \\
DIP & 0.015 & 0.012 & 0.01 & 0.01 & 0.01 & 0.007 & 0.009 & 0.009 & 0.01 \\
TRA & 0.4 & 0.5 & 0.5 & 0.5 & 1 & 1 & 1.4 & 1.5 & 0.85 \\
\hline
\end{tabular}

SAL: Salinity, TRA: Transparency, COD: Chemical oxygen demand (mg/L); DIN: Inorganic nitrogen (mg/L), DIP: Reactive phosphate (mg/L).

Mean salinity values in investigated sea waters were significantly higher than the mean salinity value, 32.8, of Laizhou Bay and its distribution showed a decline trend from coastal drain outlets to the outside with a great varying gradient. LZW4 and LZW6 were areas of high salinity around main drain outlets of the Industrial Park with discharge of highest salinity. The minimum salinity appeared in LZW3, but it was still higher than the typical index of salinity in inshore waters of an estuary which required $<27$.

Concentrations of nutritive salts and COD monitored in investigated sea waters were obviously lower than those in the same period in previous years. For distribution of concentrations, it showed a 
gradual decline trend from the estuary to open seas and from the estuarine plume front to eastern coastal waters and LZW1 within the estuary had the highest monitoring value.

Distribution of water transparency showed a characteristic of gradual increase from the estuarine plume front to eastern coastal waters and the transparency of LZW1, LZW2 and LZW3 located in the estuarine plume front was less than $1 \mathrm{~m}$.

Phytoplankton composition and abundance. 17 genera and 25 species of phytoplankton were found in the survey area, among which 13 genera and 20 species, accounting for $80 \%$ of the total, belonged to bacillariophyta and 4 genera and 5 species, accounting for $20 \%$ of the total, belonged to pyrroptata. In bacillariophyta, Chaetoceros, Coscinodiscus and Nitzschia were the most, while in pyrroptata, Ceratium dominated. The horizontal distribution of numbers of phytoplankton species showed an upward trend from estuaries and coasts to the outside (Fig. 2 (a)). With the highest salinity, LZW6 had the lowest number of phytoplankton species, only 5. Compared to the same period historically, the number of phytoplankton species was lower and nearshore eurythermic euryhaline species dominated. Only one type of nearshore low-salt rhizosolenia appeared. At the same time, the proportion of oversea high-salt species such as Coscinodiscus radiates, Cos. asteromphalus and Ch. debilis, increased and they primarily appeared around off-shore sites and LZW6 with very high salinity. This mainly resulted from high-concentration salt-containing wastewater discharge in east coasts, a narrow specie range of phytoplankton that is suitable for the high-salinity environment and selectivity of sea area environments to adaptive species of phytoplankton.

The dominance $Y$ of Melosira sulcata, Skeletonema costatum, Chaetoceros spp., Leptocylindrus and Cos. asteromphalus was $0.133,0.076,0.048,0.044$ and 0.032 respectively. The cell abundance of these dominant species accounted for $74.75 \%$ of the total. As the main dominant specie in most of China's estuaries, Skeletonema costatum only appeared in Jiaolai Estuary and the estuarine plume front in this survey, while its abundance in LZW1 inside the estuary was little where the concentrations of seston and salts were obviously higher than those in other sites. Cos. asteromphalus, a high-salt specie adaptive to salinity of 30 became a dominant specie, indicating the high salinization of the investigated sea waters.
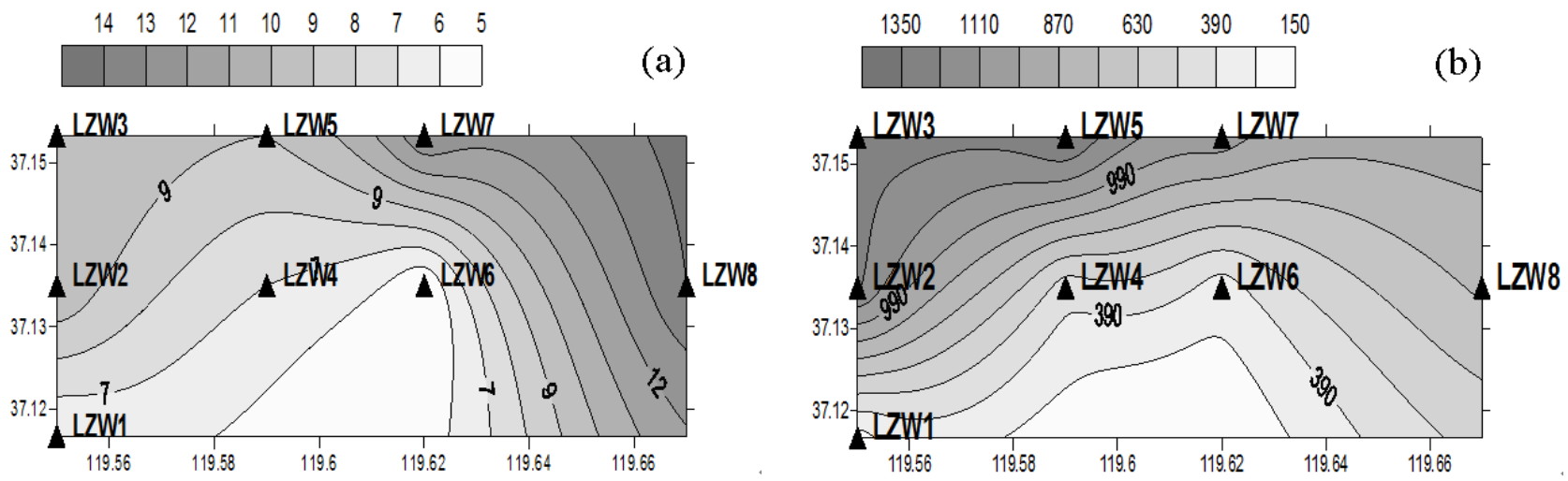

Fig. 2 (a) Horizontal distribution of numbers of phytoplankton species, (b) Horizontal distribution of phytoplankton abundance $\left(\times 10^{3}\right.$ cells $\left./ \mathrm{m}^{3}\right)$.

The change range of phytoplankton cell abundance of the investigated sea waters was between $218.2 \times 10^{3}-1375.6 \times 10^{3}$ cells $/ \mathrm{m}^{3}$ with an average value of $834.5 \times 10^{3} \mathrm{cells} / \mathrm{m}^{3}$, which was lower than those in the same period of the previous years. In each site, the mean cell abundance of diatom was $819.2 \times 10^{3} \mathrm{cells} / \mathrm{m}^{3}$ and that of dinoflagellate was $15.3 \times 10^{3}$ cells $/ \mathrm{m}^{3}$. In bacillariophyta, the cell abundance of Melosira sulcata was in the first place and accounted for $27.01 \%$ of the total, followed by Skeletonema costatum and Chaetoceros spp., accounting for $20.86 \%$ and $18.11 \%$ respectively. In pyrroptata, the cell abundance of peridinium was of absolute advantage and accounted for $70 \%$ of the total. The horizontal distribution of cell abundance of phytoplankton was shown in Fig. 2(b) with an increasing trend from nearshore to off-shore. Low-value area was situated in LZW1 inside the Jiaolai Estuary and LZW4, LZW6 near industrial discharge outlets in east coasts. Their phytoplankton cell abundance was lower than $500 \times 10^{3}$ cells $/ \mathrm{m}^{3}$ with a minimum value of $324 \times 10^{3} \mathrm{cells} / \mathrm{m}^{3}$. 
Diversity indexes of phytoplankton community. Diversity indexes of phytoplankton were shown in Tab. 2. Higher index value represents better biodiversity. High-value areas of three indexes were in LZW7 and LZW8 which were far away from estuaries and coastal discharge outlets, while low-value areas were in LZW4 and LZW6 where biotope conditions were bad. LZW4, which had the lowest index, lied in the intersection of the estuary region and coastal high-salt waters and had 7 species with abundance of only $442.8 \times 10^{3}$ cells $/ \mathrm{m}^{3}$. However, the abundance of Melosira sulcata itself accounted for $76.47 \%$. Limited species and single dominant specie impacted the diversity of this site.

Tab.2 The biodiversity indexes of phytoplankton in Jiaolai estuary and its adjacent waters

\begin{tabular}{cccccccccc}
\hline Index & LZW1 & LZW2 & LZW3 & LZW4 & LZW5 & LZW6 & LZW7 & LZW8 & Mean \\
\hline$D$ & 0.93 & 1.26 & 1.26 & 0.98 & 1.11 & 0.69 & 1.72 & 1.96 & 1.24 \\
$J$ & 0.75 & 0.73 & 0.79 & 0.49 & 0.60 & 0.56 & 0.75 & 0.71 & 0.67 \\
$H^{\prime}$ & 1.93 & 1.85 & 2.64 & 1.37 & 1.92 & 1.69 & 2.79 & 2.69 & 2.11 \\
\hline
\end{tabular}

Multivariate statistical analysis. Based on the matrix of Bray-Curtis specie abundance level similarity, cluster analysis of phytoplankton in 8 sites was carried out by an inter-group average method (Fig. 3). 35\% of similarity was selected as a standard (the dotted line). 8 sites were divided into three groups. Group I was located in Jiaolai Estuary and its estuarine plume front and consisted of LZW1, LZW2 and LZW3; Group II was distributed in east coasts of Jiaolai Estuary to the far east sea and included LZW4, LZW5, LZW7 and LZW8; and LZW6 constituted group III alone. In a MDS sequence diagram based on the same similarity (Fig. 4), grouping results were in accordance with cluster analysis and spatial distances to each group were large with significant differences and Stress $=0.06<0.1$, which could explain similar relations among groups correctly.

Results of the ANOSIM significance test of difference showed, $\mathrm{R}=0.93>5 \%$ and $\mathrm{P}(1 \mathrm{evel} \%)=0.4 \%$ $<0.05$. Difference tests of any two groups of the three was carried out. $\mathrm{R}>0.8$ and $\mathrm{P}<0.05$ indicated significant differences among groups, so it verified the validity of cluster analysis results statistically.

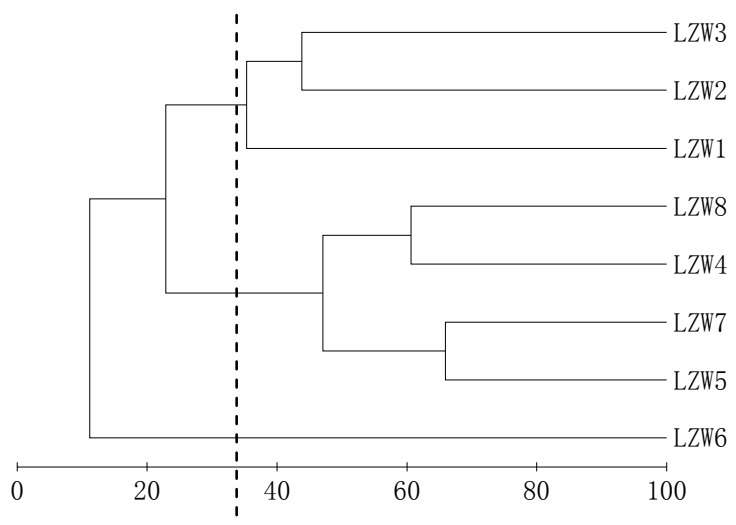

Fig.3 Cluster dendrogram of phytoplankton

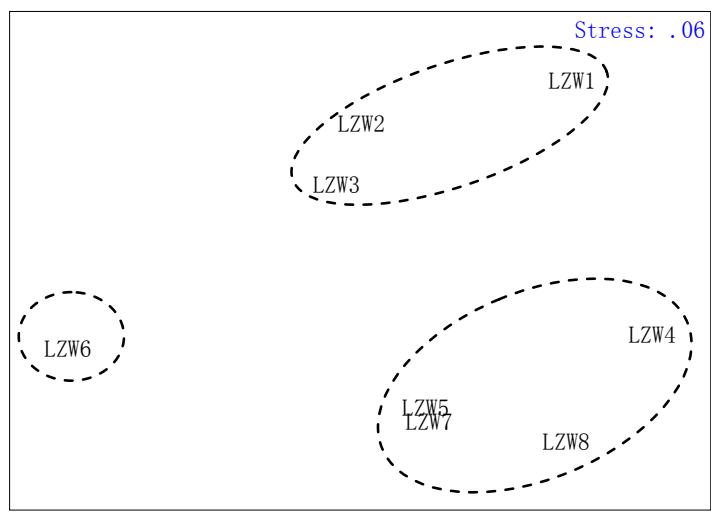

Fig.4 MDS ordination of phytoplankton

Group I basically showed distribution characteristics of estuarine phytoplankton. The waters of group I had a high concentration of nutritive salts and low salinity. However, affecting by the transparency of waters, its phytoplankton abundance and diversity were in the middle of the three groups and its dominant species were Skeletonema costatum, Chaetoceros spp. and Ch.densus. Group II showed distribution characteristics of nearshore phytoplankton. Due to proper salinity and transparency and high heterogeneity of the environmental ecotone space, a more diverse environment was provided resulting in the highest diversity and abundance of phytoplankton in this group. Its dominant species were Melosira sulcata, Bacteriastrum hyalinum and Leptocylindrus. Group III belonged to a high-salt low-nutrition region and its dominant species were Odontella sinensis, Cos. asteromphalus and Ch. debilis which were of high tolerance of salinity. 
Correlation analysis. Tab. 3 showed Pearson correlation analysis results of phytoplankton and environmental variables. Strong negative correlation was found between salinity and phytoplankton species, abundance and diversity indexes respectively. The relevance levels of abundance, $H$ ' and $J$ were significant and high-salinization waters significantly restricted reproductive growth of phytoplankton in the survey area, which was a key factor forming the phytoplankton structure of this region. Relevance of nutritive salts and COD concentrations with various ecological indexes of the phytoplankton community was not significant and did not become the major limiting factors for the growth of phytoplankton. Turbidity showed positive correlation with various ecological indexes of the phytoplankton community and relevance of specie numbers and $H$ ' reached a significant level. Influenced by the water of Jiaolai River carrying sediment and organic impurities, the estuarine plume front of Jiaolai River generated high suspensoid and a low-transparency seawater environment, affecting photosynthetic rates of phytoplankton. Turbidity was one of the important factors affecting the phytoplankton community pattern in the waters.

Tab.3 Pearson correlation coefficients between phytoplankton and environmental variables

\begin{tabular}{cccccc}
\hline Parameter & Species & Abundace & $H^{\prime}$ & $J$ & $D$ \\
\hline SAL & -0.395 & $-0.875^{* *}$ & $-0.650^{*}$ & $-0.744^{*}$ & -0.587 \\
COD & -0.501 & -0.072 & -0.352 & 0.267 & -0.461 \\
DIN & -0.009 & -0.031 & -0.470 & 0.107 & -0.153 \\
DIP & -0.423 & -0.116 & -0.162 & 0.403 & -0.152 \\
TRA & $0.889^{* *}$ & 0.740 & $0.561^{*}$ & 0.421 & 0.659 \\
\hline
\end{tabular}

*. for $\mathrm{P}<0.05$; **. for $\mathrm{P}<0.01$.

\section{Conclusions}

1) Impacted by wastewater discharged from the industrial park along the coasts, water quality of Jiaolai Estuary of Laizhou Bay presented a high-salt and low-nutrition status. Species and abundance of phytoplankton in investigated sea waters shrank obviously. Estuarine freshwater species were replaced by coastal euryhaline species and high-salt species which became the main ecological types of phytoplankton .2) Phytoplankton in the investigated waters could be divided into three ecological groups and differences of environmental factors and ecological characteristics among each groups were significant. Due to different inner demands of growth and reproduction of phytoplankton, an unique spatial distribution pattern of phytoplankton cluster in the waters was formed. Salinity and water transparency played important roles in phytoplankton distribution of the whole sea area, while nutrient salts had no obvious effect.3) Research results indicated that the ecological environment of the investigated waters was destroyed and effective measures should be implemented in time to carry out pollution control and ecological protection.

\section{References}

[1] C. Liu, L. Liu and H. Shen: Procedia Environ. Sci. Vol.2 (2010), p. 1622-1631.

[2] J. Padisak, E. Hajnal and L. Naselli-Flores: Hydrobiologia Vol.639 (2010), p. 205-220.

[3] O. SHANE, S. JOE: J. Plankton R. Vol.32 (2010), p. 99-118.

[4] R. E. Ulanowicz: Compu. Chem. Vol.25 (2001), p. 393-399.

[5] K. R. Clarke, R. M. Warwick: Change in Marine Communities: An Approach to Statistical Analysis and Interpretation. ( PRIMER-E Ltd, Plymouth 2001). 